\title{
Early diagnosis of autism and impact on prognosis: a narrative review
}

This article was published in the following Dove Press journal:

Clinical Epidemiology

20 February 2013

Number of times this article has been viewed

Elisabeth Fernell'

Mats Anders Eriksson ${ }^{1,2}$

Christopher Gillberg'

'Gillberg Neuropsychiatry Centre, Sahlgrenska Academy, University of Gothenburg, Gothenburg, Sweden; ${ }^{2}$ Department of Women's Institute, Stockholm, Sweden and Children's Health, Karolinska
Correspondence: Elisabeth Fernell

Tel +46 3I 3425970

Fax +46 3I 3425979

Email elisabeth.fernell@gnc.gu.se

\begin{abstract}
Autism spectrum disorders involve a set of clinical phenotypes that mirror an early onset of neurodevelopmental deviations, with core symptoms that can probably be related to a deficiency in the social instinct. Underlying the cognitive impairments there are physiological brain problems, caused by a large number of medical factors. This narrative review of systematic reviews and meta-analyses from the last 5 years (2008-2012) presents aspects from many areas in autism spectrum disorder research, with a particular focus on early intervention and the subsequent impact on prognosis. Other major areas discussed are epidemiology, early symptoms and screening, early diagnosis, neuropsychology, medical factors, and the existence of comorbidities. There is limited evidence that any of the broadband "early intervention" programs are effective in changing the natural long-term outcome for many individuals with an early diagnosis of autism. However, there is some evidence that Early Intensive Behavioral Intervention (EIBI) is an effective treatment for some children with ASD. Nevertheless, there is emerging consensus that early diagnosis and information are needed in order that an autismfriendly environment be "created" around affected individuals.
\end{abstract}

Keywords: autism spectrum disorder, epidemiology, screening, etiology, intervention, outcome

\section{Introduction}

Autism, now increasingly referred to as autism spectrum disorder (ASD), is a clinical presentation - or rather a set of clinical phenotypes - mirroring an earlyonset neurodevelopmental disorder affecting social communication, imagination, and behavior. ${ }^{1,2}$ There are several other named disorders (intellectual disability [ID], developmental coordination disorder [DCD], communication disorders affecting language, attention-deficit/hyperactivity disorder [ADHD], and tic disorders including Tourette's syndrome) that overlap to a large extent with autism and which can be difficult to separate out from one another, particularly at the early stages of development. This group of disorders is now often referred to as ESSENCE (early symptomatic syndromes eliciting neurodevelopmental clinical examinations). ${ }^{3}$

\section{Methods}

This review involved a search of the PubMed database for systematic reviews and meta-analyses published within the last 5 years, 2008-2012. The following combined search terms were used: autism, children, intervention, outcome, systematic review, and meta-analysis. Only studies reporting cognitive behavioral interventions and outcome in a broad perspective (ie, not single aspects of outcome, such as behavior only) were included. Nine studies published during these years were found to meet 
the criteria (Table 1). In addition, the authors selected other relevant papers in the fields of ASD epidemiology, early symptoms and screening, early diagnosis, neuropsychology, medical factors, and comorbidities to complement these systematic reviews and meta-analyses.

\section{Epidemiology of autism}

Autism epidemiology will vary with diagnostic criteria. It is now commonly asserted that autism occurs in about $1 \%$ of the general population. ${ }^{4,5}$ However, nobody knows what the "true" prevalence of autism "really" is, given that there is no absolute agreement as to what exactly constitutes autism. There is superficial consensus that autism is a spectrum disorder (with severe and mild variants at endpoints of a continuum) but even that is contentious, as there are clearly several spectrum disorders within the socalled autism spectrum - at least in part related to the many different etiologies. For instance, some cases of autism are caused by $22 \mathrm{q} 11$ deletion syndrome and others are caused by Angelman syndrome, both with their own spectrum of problems within their "specific" phenotypes, and most cases of autism are caused by certain etiological factors, or combinations of etiological factors, all of which can be portrayed as being "spectrum problems." Nevertheless, with the criteria of the Diagnostic and Statistical Manual of Mental Disorders (Fourth Edition) (DSM-IV), ASD (or "pervasive developmental disorder," in the terminology of the DSM-IV), and with the implicit criterion that caseness will only be assigned in instances of clinical impairment (usually meaning need for intervention), cases of ASDs are identified in the general population of preschool children at about a rate of $0.6 \%-0.8 \%,{ }^{4,6,7}$ in school children and young adults at about $1.0 \%,{ }^{8,9}$ and in older (albeit not really "old") adults at about $1.0 \%{ }^{10}$ These rates would cover all the variants of ASD but

Table I Nine studies published between 2008 and 2012 that met the search criteria

\begin{tabular}{lll}
\hline References & $\begin{array}{l}\text { Type of } \\
\text { review }\end{array}$ & $\begin{array}{l}\text { Year of } \\
\text { publication }\end{array}$ \\
\hline Parr J $^{72}$ & Systematic review & 2010 \\
Reichow et al $^{73}$ & Systematic review & 2012 \\
Eldevik et al $^{74}$ & Meta-analysis & 2009 \\
Virués-Ortega J $^{76}$ & Meta-analysis & 2010 \\
Warren et al $^{102}$ & Systematic review & 2011 \\
Howlin et al $^{99}$ & Systematic review & 2009 \\
Reichow B & Overview of meta-analyses & 2012 \\
Ospina et al & Systematic review & 2008 \\
Spreckley and & Systematic review and & 2009 \\
Boyd & meta-analysis & \\
\hline
\end{tabular}

not those of autistic traits without clinical impairment, which apply to three or four times as many individuals of the general population of young children. ${ }^{11,12}$

Boys are believed to be affected by autism much more often than girls, and male-to-female ratios of 3-5:1 are often reported. ${ }^{13}$ However, many recent studies suggest that girls and women with slightly different phenotypes may have the same underlying social communication disorders that are typical of boys and men with a diagnosis of autism, ${ }^{14}$ and so the "real" male-to-female ratio might be much lower and closer to the 1.1:2.0 ratios often reported for other neurodevelopmental disorders such as ID.

\section{Characterization of symptoms and diagnosis of autism}

The basic symptom in autism, if one exists, has been suggested to be a primary (usually "inborn") deficiency in social instinct. ${ }^{15}$ This would show up early in life as a lack of, or at least a marked decrease in, the drive for social communication. All of the following examples could be construed as stemming from the same basic deficit in social instinct: lack of eye direction detection, self-initiated joint attention, pointing with "triangulation" (ie, looking at the face of the caregiver when faced with something unfamiliar), speech for communication, early development of theory of mind skills, attention to socially relevant stimuli in the environment, and perhaps even the typical "local processing style" or lack of central coherence.

It has been impossible to pinpoint any pathognomonic symptom of autism. ${ }^{2}$ Rather, various attempts at capturing the "autism gestalt" have been published around sets of operationalized symptom criteria (American Psychiatric Association, 1980, 1987, 1994, 2012), ${ }^{16}$ most of which have relied on Wing's ${ }^{17}$ suggested triad of social, communication, and imagination (as reflected in behavior) impairments. The DSM-IV criteria for autistic disorder have been around for about 20 years and are widely accepted as "normative" for the clinical (and research) gestalt of autism. The Gillberg and Gillberg ${ }^{18}$ criteria for Asperger's syndrome have been used for about 25 years and are the ones in widespread clinical use for higher-functioning individuals presenting with an "autism phenotype"; DSM-IV criteria for Asperger's disorder have been shown not to be consistent either with Asperger's own clinical case descriptions ${ }^{19,20}$ or with the clinical presentation of patients presenting at "autism and Asperger's clinics." ${ }^{21}$ The proposed DSM-5 criteria have resulted in vociferous criticism, ${ }^{2,15,22,23}$ mostly because of their implication that there exists such a "thing" as a unique and narrow phenotype of autism. 
Underlying the basic symptoms in autism there are a number of neuropsychological and/or social cognitive problems that can be categorized under different headings. Here the authors will briefly review these and suggest how knowledge in this field should influence what is done in clinical practice in terms of neuropsychological workup. Underlying the neuropsychological and social cognitive dysfunctions there are a number of physiological brain problems, which, in turn are caused by a number of specific and unspecific medical factors. Following the neuropsychological review, the authors will present clinical guidance for the medical workup that is needed in all cases of autism.

\section{Neuropsychology}

The neuropsychological assessment forms an important part of the total clinical workup. Many children with ASDs present with co-occurring low general cognitive function and may be diagnosed with borderline intelligence quotient (IQ), mild ID, or moderate to severe ID. In addition, an uneven cognitive profile is often demonstrated at neuropsychological tests, most often with lower verbal skills than nonverbal abilities, even though in the Asperger's syndrome group the profile is often reversed. Clinically, general cognitive impairment in association with ASDs should be recognized and considered, since it will be of the utmost importance for intervention and it will have a strong impact on development and outcome. To establish a definitive IQ level is not always possible in the youngest preschool children, but a follow-up assessment of the child's general cognitive ability should be performed before school start. There are also many specific cognitive deficits - of different severities and with different expressions - that are also influenced by the child's general cognitive ability. The deficient social instinct, "theory of mind," is often the most significant cognitive impairment in individuals with ASDs. Weak central coherence, ${ }^{24}$ narrow focus and difficulty redirecting attention, ${ }^{25}$ and executive dysfunctions of various kinds $^{26}$ also characterize the cognitive profiles of many children with ASDs.

\section{Neuroimaging}

Neuroimaging studies of anatomy and of functional connectivity have demonstrated that underlying brain pathology in ASDs is not localized to a specific brain region but involves alterations in brain networks that reflect reduced connectivity in a variety of brain regions. ${ }^{27-29}$ The prefrontal, temporal, brainstem, and cerebellar regions of the central nervous system are usually affected. These parts of the brain constitute a functional "default network" ${ }^{30}$ needed for theory of mind processing and executive function, and these parts appear to be critically differently functioning in autism. ${ }^{31}$ The decreased inter- and intranetwork connectivity has been well established in many cases of autism, ${ }^{32}$ and this may be linked to increased peripheral processing (and, possibly, to decrease in drive for central coherence). Mirror neurons may play a role but are clearly not specifically dysfunctional in autism. ${ }^{33}$

\section{Medical workup}

It has been clear for a long time, although not reflected in the bulk of research and clinical work to date, that autism (or rather, "autisms" in the plural) is a group of multifactorially determined conditions (not really one spectrum as the term ASD suggests) with multiple comorbidities, which are often more impairing than "the autism per se" (eg, ID, DCD, epilepsy, ADHD). ${ }^{1-3}$ There are almost as many causes as there are cases. Even Down syndrome, once felt to represent "the opposite of autism," can present with the combination of ASD and ID. ${ }^{34}$

Despite the convincing genetic basis for ASDs, ${ }^{35}$ a definite cause remains unknown in most individual cases. The majority of ASDs are probably caused by complex interaction between multiple genes (oligo- and polygenic models). Environmental and epigenetic factors may modulate gene expression, and variation in penetrance and expressivity of influential genes add to the broad diversity of clinical presentations. $^{36}$

Prenatal environmental factors contribute to the clinical presentation in many cases and probably even themselves cause the disorder in some instances. Intrauterine congenital central nervous system infections also increase the risk of ASDs (rubella, cytomegalovirus). ${ }^{37}$

Several studies have shown an increased risk for cognitive problems including ASDs in children born extremely preterm. ${ }^{38}$ Intrauterine exposure to harmful agents such as sodium valproate strongly increases the risk for ASDs. ${ }^{39}$

Peri- and postnatal traumatic brain injury, cerebrovascular lesions, severe encephalopathy, and brain infections (herpes simplex, cytomegalovirus) may lead to the development of autistic symptoms.

A medical or genetic condition can be identified in about $10 \%-25 \%$ of children with ASDs, depending on the sample and the diagnostic tools. Autism susceptibility is currently associated with at least 200 risk genes, with the number of disease genes continuously rising. ${ }^{40}$ Many of the genetic causes of ASDs have also been identified as causes of ID, indicating a shared genetic basis. All types of inheritance 
are represented, including autosomal dominant, autosomal recessive, and $\mathrm{X}$-linked.

Sex chromosome aneuploidies are implicated in a number of ASD cases. ${ }^{1}$ Many single-gene disorders present with autistic features or ASDs and therefore need to be considered. Tuberous sclerosis, fragile $\mathrm{X}$ syndrome and, in girls, Rett syndrome are the most common. Testing for fragile X syndrome should always be considered in both boys and girls with ASDs. In girls with an ID and ASD the possibility of Rett syndrome should always be borne in mind.

Copy number variants (CNVs), defined as an abnormal number of copies of a DNA-segment with a size larger than $1 \mathrm{~kb}$, play a role in the human genetic variation. It has been shown that children with ASDs have an increased burden of both de novo and inherited CNVs compared with siblings and controls. With higher-resolution array-based techniques, gene dose imbalances, due to copy number variations (CNVs), are found in $7 \%-10 \%$ of children with ASDs versus $1 \%$ in controls. $^{41}$

Chromosomal microarray analysis identifies many common causes of ASDs, such as the maternal duplication in chromosome band 15q11-q13; microdeletions and microduplications in 16p11.2, 22q11, and 22q13 deletion syndromes; Potocki-Lupski syndrome; and some cases with Angelman syndrome. Microarray-based genetic testing in diagnostic assessment of children with ASDs should be discussed and offered in all cases, and particularly in cases with ASD and an ID or multiple congenital abnormalities. ${ }^{42}$ The microarray testing can, in many cases, replace conventional karyotyping.

A frequently replicated finding in children with ASDs and other ESSENCE is that identified genomic imbalances interrupt genes important for synaptic formation and function. Implicated genes include the SHANK1, SHANK2, and SHANK3 genes (SHANK3 is disrupted in 22q13.3 deletion syndrome); ${ }^{43}$ the NRXN1 gene, affected in deletion $2 \mathrm{p} 16.3 ;{ }^{44}$ the CNTNAP2 gene, in deletion $7 \mathrm{q} 35-\mathrm{q} 36,{ }^{45}$ and the postsynaptic neuroligin genes, NLGN3 and NLGN4, on the $\mathrm{X}$ chromosome. ${ }^{46}$

Children with ASDs have an increased risk for co-occurring epilepsy. ${ }^{47,48}$ The prevalence of epilepsy in children with ASDs is often, but not always, linked to ID. However, the rate of epilepsy in subjects with ASDs without cognitive impairment is $8 \%$, a much higher prevalence than in the general population. Furthermore, in children with epilepsy there is an increased risk of ASDs - most evident in children with early-onset epilepsy. ${ }^{49}$ Coexisting ASD is found in $37 \%$ of children with an ID and active epilepsy. ${ }^{50}$
In about $20 \%$ of children with ASDs (often at an age of 15-30 months) a regression in the child's development with loss of skills is reported. The relationship between autistic regression and epilepsy remains controversial. ${ }^{51,52}$ In children with loss of language skills, sleep electroencephalography is clearly indicated. An abnormal electroencephalogram may reflect underlying brain dysfunction. Treatment with antiepileptic medication has not been generally effective in reducing autistic core symptoms, but it may be indicated in some circumstances. Brain magnetic resonance imaging is not indicated in most cases but it can be advocated in children with autism and epilepsy.

Inborn errors of metabolism may present with ASDs, with or without IDs, but they account for only a small fraction of children with ASDs. Mitochondrial disorders need to be considered if there is a history of "energy crisis symptoms." If associated motor symptoms are present, the etiological considerations need to include a larger group of neuromuscular disorders. ${ }^{53-55}$

The physical examination of each child must include growth data with head circumference, careful examination for any dysmorphology, inspection of the skin (tuberous sclerosis, neurofibromatosis, hypomelanosis of Ito), evaluation of fine and gross motor function, and basic neurologic assessment of muscle tone, gait, and reflexes. In many cases hearing and visual function also need to be examined.

\section{Early symptoms, screening, and diagnosis}

There is general agreement that ASDs should be identified as early in life as possible, with a view to ensuring that intervention can start as quickly as possible. Currently, there are efforts being made to find methods for very early identification of impaired joint attention and there are ongoing studies following "new" siblings of children with autism. ${ }^{56}$ However, because of the extremely heterogeneous etiology of autism, with varying degrees of associated brain disorder, time of identification will probably have to vary.

The CHAT (Checklist for Autism in Toddlers) was developed by Baron-Cohen et $\mathrm{al}^{57}$ and was later extended to the Modified CHAT or M-CHAT. ${ }^{58}$ Nygren et al ${ }^{59}$ evaluated a new screening program for autism in a general population of 5000 Swedish children aged $2 \frac{1}{2}$ years. The authors used a combination of instruments - namely, structured training of all nurses in child health centers, the M-CHAT, and an observation of the child's joint attention together with a short language screen - and found a very high 
positive predictive value when this combination of tools was used $(90 \%)$.

In some children with ASDs there is an early onset of regulatory problems (Barnevik-Olsson et al, unpublished data, 2013), such as with sleeping, ${ }^{60}$ crying, ${ }^{61}$ and feeding. ${ }^{62}$ The importance of identifying autism at an early age has been stressed in many studies. ${ }^{63,64}$ The early identification of ASDs allows for early onset of adapted behavioral and educational measures and information to parents and preschool staff about the child's underlying cognitive problems. However, when discussing the advantages of early diagnosis and early start of intervention in relation to outcome, the child's developmental profile, comorbidities, and medical disorders must also be considered. In a naturalistic follow-up study of preschool children with ASDs who were receiving early intervention, those who had had an ASD diagnosis established very early (and therefore had received an early start of intervention) did not exhibit a better outcome than children with a later diagnosis (and hence a later start of intervention during the preschool age period). When medical aspects were factored in, it was found that the children who had been diagnosed with ASDs at a very early age had more medical disorders identified, and in turn, these children more often had IDs. ${ }^{65}$ It was also found that the group of children with any medical or genetic condition, including epilepsy, had a significantly lower Vineland composite score at the 2-year follow-up than the group without such disorders.

A diagnosis of autism has been demonstrated to be stable over time ${ }^{66}$ while children diagnosed with atypical autism or pervasive developmental disorder not otherwise specified have been shown to change with regard to diagnostic category in a considerable number of cases. ${ }^{67,68}$ These findings emphasize the need for clinical follow-up and reassessments of children diagnosed with ASDs, especially during the preschool years.

\section{Early intervention programs available}

There are now a number of early intervention programs available that are purportedly more or less specifically focused on autism. Basically, there are two major groups of such programs ${ }^{69}$ one linked to theories of applied behavior analysis $(\mathrm{ABA})^{70}$ and another to "philosophies" centered on structured education, and often subsumed under the TEACCH acronym (Treatment and Education of Autistic and related Communication handicapped CHildren). ${ }^{71}$ In short, ABA is founded on basic principles of learning, motivation, and positive reinforcement and TEACCH emphasizes visual work systems, positive routines, and structured teaching. Both sets of programs involve parents in the training procedures.

\section{Efficacy and safety and outcome of early intervention}

The overall objectives of early intervention in autism are to improve social function, communication, and other cognitive abilities and to reduce repetitive and obsessional behaviors, while also minimizing any adverse effects of the intervention. A comprehensive, systematic review with regard to efficacy and safety of different types of interventions has been presented by Parr. ${ }^{72}$ This review included (1) early multidisciplinary intervention programs, (2) dietary interventions, (3) drug treatments, and (4) nondrug treatments. Among programs referred to, the group of early multidisciplinary interventions (early intensive behavioral interventions [EIBIs], the Picture Exchange Communication System, More Than Words, and the TEACCH approach) were classified as likely to be beneficial, while most other programs (of those mentioned in the review) were found to be of unknown effectiveness. Among drugs, methylphenidate was found likely to be effective for hyperactivity. ${ }^{72}$

The evidence regarding the efficacy and safety of early interventions in autism is still limited. ${ }^{73,74}$ In a meta-analysis by Eldevik et $\mathrm{al}^{75}$ that involved nine controlled studies, a standardized mean difference effect size for two available outcome measures, change in full-scale intelligence and/or adaptive behavior composite, was demonstrated. In a metaanalysis by Virués-Ortega ${ }^{76}$ comparable effects of ABA were reported. However, methodological issues, with regard to quality standards, such as various methods, designs, and treatment features were also discussed.

Most authors agree that EIBIs result in some improved outcomes in the short- and intermediate-term perspective, ${ }^{77-86}$ but there is considerable variability with EIBIs, being effective in subgroups of, but far from all, preschool children with autism. Despite the relative dearth of robust randomized controlled trial (RCT) evidence, there is limited consensus, based on clinical experience, that EIBIs are likely to be beneficial. In a recent Cochrane Database Systematic Review on EIBI for young children with ASDs it was concluded that there is some limited evidence that EIBI is an effective behavioral treatment for some children with ASDs. ${ }^{74}$ However, the current state of the evidence is limited because of the reliance on data from nonrandomized studies due to the relative lack of RCTs. Additional studies using RCT research designs are needed to draw conclusions about the effects of EIBI for children with ASDs. ${ }^{72,74}$ 
RCTs are often considered the gold standard in intervention studies. However, this view has recently been challenged specifically in relation to study design when it comes to children with complex developmental disorders such as autism. ${ }^{87-89}$ Moreover, in ASD intervention research using RCT techniques, children with major additional disabilities, coexisting medical disorders, epilepsy and/or severe IDs are usually excluded. This creates artificial conditions that are not representative of clinical reality. The present authors would like to add that RCTs alone cannot determine the long-term effectiveness of any intervention in disorders that are developmental in nature.

Given that there have not been any large scale studies regarding highly individualized interventions for autism, and the difficulty of integrating findings from RCTs - that can only really ever be performed with rigor over relatively brief periods of time - with those of essential naturalistic long-term outcome studies, the "evidence-basis" is limited and recommendations, by default, based more on clinical long-term experience than on "hard research fact." Smallscale RCTs have provided some restricted evidence that ABA-based intensive interventions can be helpful for some young children with autism. ${ }^{86}$

Children in the EIBI programs usually receive $20-40$ hours per week of intervention, and advantages with regard to outcome have been demonstrated with increased intensity, as reflected by a higher number of treatment hours per week. ${ }^{90}$ However, larger-scale naturalistic studies making use of these same ABA techniques or others have been unable to find any support for the intensity of the intervention being important in a positive way but that targeted, brief ABA interventions can improve social communication in young children with ASDs - to the same degree as more intensive interventions. $^{71,91-94}$

Many outcome studies have highlighted the importance of the child's IQ. This factor has been demonstrated to have a very strong and independent influence on outcome with regard to adaptive functioning, quite regardless of the intensities of the intervention given. ${ }^{71}$ In a retrospective study it was reported that preschool children with autism, without ID, who had received early ABA treatment had improved considerably with regard to both IQ and adaptive functioning. ${ }^{95}$ These preliminary findings need to be replicated in prospective RCTs and naturalistic studies before any conclusions can be drawn.

Some Swedish outcome studies, carried out before the introduction of early intervention programs, have revealed a poor prognosis for many individuals with ASDs. In a prospective long-term follow-up study, 120 individuals diagnosed in childhood were reevaluated at ages between 17 and 40 years with regard to outcome based on employment, higher education or vocational training, independent living, and peer relationships. Overall outcome was found to be poor in $78 \%$ of cases. Only four individuals were independent, albeit leading fairly isolated lives. Childhood IQ level was positively correlated with better adult outcome, as was the existence of some communicative phrase speech at the age of 6 years. ${ }^{96} \mathrm{~A}$ similar prognosis, with $59 \%$ showing a poor or very poor outcome, was also reported in a previous Swedish study. ${ }^{97}$ In a prospective follow-up study of 70 males with Asperger's syndrome and 70 males with autism, outcome was found to be good in $27 \%$ of those with Asperger's syndrome; however, a similar proportion was found to live a very restricted life, with no occupation or activity and no friends. Outcome in the autism group was significantly worse. ${ }^{98}$

Howlin et al's ${ }^{99}$ systematic review of controlled studies of EIBIs for young children with autism showed that at group level, EIBI resulted in improved outcomes (primarily measured by IQ) compared with comparison groups. At an individual level, however, there was considerable variability in outcome, with some evidence that initial IQ (but not age) was related to progress. The review provides some evidence for the effectiveness of EIBI for some, but not all, preschool children with autism. Reichow's ${ }^{100}$ overview of five metaanalyses shows that, on average, EIBI can be a powerful intervention capable of producing large gains in IQ and/or adaptive behavior for many young children with ASDs.

Ospina et al' ${ }^{101}$ review concludes that no definitive behavioral or developmental intervention improves all symptoms for all individuals with ASDs, and the authors recommended that clinical management should be guided by individual needs and availability of resources.

In a review by Warren et $\mathrm{al}^{102}$ that covers studies from 2000 to 2010, some evidence was found to support the argument that early intensive behavioral and developmental intervention is beneficial for improving cognitive performance, language skills, and adaptive behavior in certain groups of children with autism. The authors highlighted both the need for replication and the importance of clinical characterization of the children who are the ones most likely to benefit from intensive interventions. It was pointed out that there are many factors that need to be better studied, including modifiers of effectiveness, generalization of effects outside the treatment context, and predictors of treatment success. ${ }^{102}$

In a systematic review of RCTs or quasi-randomized controlled studies by Spreckley and Boyd, ${ }^{103}$ outcome after 
applied behavior intervention or standard care in young children with ASDs was compared. The authors found no evidence that applied behavior intervention gave better outcome than standard care. ${ }^{103}$

\section{Methods of raising parental awareness and preschool initiatives}

Almost all currently available intervention programs stress the importance of parental involvement from the start. ${ }^{100}$ The needs of parents with regard to basic education around ASDs are increasingly highlighted, and parental educational programs are now provided from habilitation services. Most also emphasize the need for "autism-friendly" preschool environments, which means that preschool staff need to be highly aware of the specific cognitive and perceptual deficits present in children with ASDs and that treatment and all daily activities should be adapted accordingly. ${ }^{104}$

\section{Comorbidities}

The common coexistence of more than one developmental disorder in an individual child is an almost universal truth for children with ASDs. ${ }^{3}$ The reported proportion of children with ASDs who also have IDs varies according to type of ASD and age group studied. In a group of preschool children with pervasive developmental disorder, Chakrabarti and Fombonne ${ }^{105}$ reported a prevalence of $26 \%$ with IDs. In a group of 987 children (aged 3-10 years) with autistic disorder, pervasive developmental disorder not otherwise specified, or Asperger's disorder, 68\% had IDs. ${ }^{106}$ Baird et al ${ }^{107}$ found IDs to be present in $56 \%$ of all cases with ASDs, aged 9-10 years, and in $73 \%$ of those with the narrow definition of autism. In a recent population-based study of preschool children with all types of ASD who were followed over a 2 -year period, the rate of ID (severe to mild) at follow-up between the ages of $4 \frac{1}{2}$ and $6 \frac{1}{2}$ years was $48 \%$. $^{71}$ When all cases of ASD in the population are included in prevalence studies, the most likely rate of "comorbidity" of ID in ASD is around 15\%-20\%. Low IQ in itself is also the strongest predictor there is of poor outcome in terms of adaptive functioning in ASDs.

The comorbidity of ASD and ID increases the risk of associated behavioral problems and it has been demonstrated that the lower the IQ, the more challenging the behavior. ${ }^{108}$

Coexistent ADHD is common in patients with ASDs and has been estimated to be around $30 \%$ in epidemiologically based studies. ${ }^{109-111}$

The coexistence of DCD - formerly often referred to as "clumsy child syndrome" - in children with ASDs, especially in those with Asperger's syndrome, has been highlighted. ${ }^{112}$
Gillberg and Kadesjö ${ }^{112}$ have emphasized the importance of awareness, in both child psychiatry and child neurology, of this common motor problem in children with ASDs.

Tics and Tourette's syndrome are extremely common in individuals with autism, perhaps particularly in those with higher IQ. ${ }^{107}$ It is possible that the emergence of tics in individuals who meet diagnostic criteria for ASDs in early life could be an indicator of a good outcome ${ }^{113}$ and that this "effect" of tics on autism outcome could possibly be mediated by generally higher IQ levels in this subgroup of patients.

Bipolar disorder is possibly markedly overrepresented in ASDs, but this specific "comorbidity" has not been much studied in recent years. ${ }^{114}$

It has been pointed out that among co-occurring psychiatric disorders in ASDs, depression is probably the most common disorder. ${ }^{115}$ The authors discussed diagnostic aspects, the contribution of genetic and environmental factors, and the importance of awareness and interventions.

The overlap between schizophrenia and ASDs has been studied by analyzing early neurodevelopmental problems (comprehensive parental interviews) in patients diagnosed with schizophrenia. About half of the cases with a clinical and research diagnosis of a schizophrenic psychosis also met criteria for ASDs, according to results obtained at parental interview. ${ }^{116}$

From an adult perspective, a considerable overlap in symptoms between Asperger's syndrome and certain personality disorders has been reported. ${ }^{117}$ It is of major importance for adult psychiatry to be aware of the possibility of an underlying ASD in patients diagnosed with personality disorders. If criteria for an ASD diagnosis are met, this will probably enable a more tailored or bespoke intervention.

Common challenging behaviors in children with autism are violent outbursts, disruptions or tantrums, impulsivity, self-injurious behaviors, and stereotypies. ${ }^{118}$ These behaviors are the targets of many intervention programs for children with autism.

Anxiety and other emotional and related behavioral problems have been reported in children with ASDs. These are important symptoms with implications for designing appropriate support services for children and families. ${ }^{119}$

There is a high rate of co-occurring epilepsy in children with ASDs, suggesting shared underlying mechanisms. ${ }^{120}$ The disorders co-occur in about $30 \%$ of individuals with either ASD or epilepsy and there is a strong association between ID, autism, and epilepsy. ${ }^{50}$ Some authors have suggested specific peaks of seizure onset in children with autism: in early childhood and in adolescence, and also with continu- 
ing risks through adulthood. ${ }^{50}$ However, such peaks have not been supported in prospective longitudinal population-based studies of epilepsy in autism. ${ }^{121}$

\section{Conclusion}

ASD is not one disorder but many. There is no intervention that works for all individuals with a diagnosis of ASD, autistic disorder, or Asperger's syndrome. A small number of cases can be treated on a rational basis because of an established etiology.

Clinically relevant autism almost invariably coexists with a number of other neurodevelopmental problems, for which there are sometimes proven effective interventions (epilepsy, ADHD, DCD, to mention but a few). In this context, the concept of ESSENCE is helpful in directing the development of appropriate diagnostic and intervention services. ${ }^{3}$

There is limited evidence that any of the broadband "early intervention" programs are effective in changing the natural long-term outcome for many individuals with an early diagnosis of autism. However, there is some evidence that EIBI is an effective treatment for some children with ASD. Nevertheless, there is emerging consensus that early diagnosis and information are needed in order that an autismfriendly environment be "created" around affected individuals. That is to say, early diagnosis and information help in the creation of a setting in which everybody who interacts on a regular daily basis with the person with autism has state-of-the-art knowledge about the basic communication, central coherence, and theory of mind deficits in autism and how these can, at least partly, be overcome by structured, concrete modes of interaction and education, and informed by increased knowledge about the typical behaviors associated with ASDs.

\section{Disclosure}

The authors report no conflicts of interest in this work.

\section{References}

1. Coleman M, Gillberg C. The Autisms. Oxford: Oxford University Press; 2012.

2. Waterhouse L. Rethinking Autism: Variation and Complexity. London: Academic Press; 2013.

3. Gillberg C. The ESSENCE in child psychiatry: Early Symptomatic Syndromes Eliciting Neurodevelopmental Clinical Examinations. Res Dev Disabil. 2010;31(6):1543-1551.

4. Nygren G, Cederlund M, Sandberg E, et al. The prevalence of autism spectrum disorders in toddlers: a population study of 2-year-old Swedish children. J Autism Dev Disord. 2012;42(7):1491-1497.

5. Simonoff E. Autism spectrum disorder: prevalence and cause may be bound together. Br J Psychiatry. 2012;201:88-89.

6. Davidovitch M, Hemo B, Manning-Courtney P, Fombonne E. Prevalence and incidence of autism spectrum disorder in an Israeli population. J Autism Dev Disord. Epub July 27, 2012.
7. Fernell E, Gillberg C. Autism spectrum disorder diagnoses in Stockholm preschoolers. Res Dev Disabil. 2010;31(3):680-685.

8. Fombonne E. Epidemiology of pervasive developmental disorders. Pediatr Res. 2009;65(6):591-598.

9. Kočovská E, Biskupstø R, Carina Gillberg I, et al. The rising prevalence of autism: a prospective longitudinal study in the Faroe Islands. J Autism Dev Disord. 2012;42(9):1959-1966.

10. Brugha TS, McManus S, Smith J, et al. Validating two survey methods for identifying cases of autism spectrum disorder among adults in the community. Psychol Med. 2012;42(3):647-656.

11. Posserud MB, Lundervold AJ, Gillberg C. Autistic features in a total population of 7-9-year-old children assessed by the ASSQ (Autism Spectrum Screening Questionnaire). J Child Psychol Psychiatry. 2006;47(2):167-175.

12. Lundström S, Chang Z, Kerekes N, et al. Autistic-like traits and their association with mental health problems in two nationwide twin cohorts of children and adults. Psychol Med. 2011;41(11):2423-2433.

13. Fombonne E. Epidemiology of autistic disorder and other pervasive developmental disorders. J Clin Psychiatry. 2005;66 Suppl 10:3-8.

14. Kopp S, Kelly KB, Gillberg C. Girls with social and/or attention deficits: a descriptive study of 100 clinic attenders. J Atten Disord. 2010;14(2): $167-181$.

15. Wing L, Gould J, Gillberg C. Autism spectrum disorders in the DSM-V: better or worse than the DSM-IV? Res Dev Disabil. 2011;32(2): 768-773.

16. American Psychiatric Association (APA). (1980, 1987, 1994, 2012). Diagnostic and Statistical Manual of Mental Disorders (DSM-III. DSMIII-R, DSM-IV and dsm5.org), Washington, DC: American Psychiatric Association.

17. Wing L. The definition and prevalence of autism: A review. Eur Child Adolesc Psychiatry. 1993;2(1):61-74.

18. Gillberg IC, Gillberg C. Asperger syndrome: some epidemiological considerations; a research note. J Child Psychol Psychiatry. 1989; 30(4):631-638.

19. Asperger H. Die "autistischen psychopathen" im kindersalter [Autistic psychopaths in childhood]. Archiv für Psychiatrie und Nervenkrankenheiten. 1944;117:76-136. German.

20. Miller JN, Ozonoff S. Did Asperger's cases have Asperger disorder? A research note. J Child Psychol Psychiatry. 1997;38(2):247-251.

21. Leekam S, Libby S, Wing L, Gould J, Gillberg C. Comparison of ICD-10 and Gillberg's criteria for Asperger syndrome. Autism. 2000;4(1):11-28.

22. McPartland JC, Reichow B, Volkmar FR. Sensitivity and specificity of proposed DSM-5 diagnostic criteria for autism spectrum disorder. $J$ Am Acad Child Adolesc Psychiatry. 2012;51(4):368-383.

23. Ritvo ER. Postponing the proposed changes in DSM 5 for autistic spectrum disorder until new scientific evidence adequately supports them. J Autism Dev Disord. 2012;42(9):2021-2022.

24. Happé F, Frith U. The weak coherence account: detail-focused cognitive style in autism spectrum disorders. J Autism Dev Disord. 2006;36(1):5-25.

25. Orekhova EV, Tsetlin MM, Butorina AV, et al. Auditory cortex responses to clicks and sensory modulation difficulties in children with autism spectrum disorders (ASD). PloS One. 2012;7(6):e39906.

26. Happé F, Booth R, Charlton R, Hughes C. Executive function deficits in autism spectrum disorders and attention-deficit/hyperactivity disorder: examining profiles across domains and ages. Brain Cogn. 2006;61(1):25-39.

27. Castelli F, Frith C, Happé F, Frith U. Autism, Asperger syndrome and brain mechanisms for the attribution of mental states to animated shapes. Brain. 2002;125(Pt 8):1839-1849.

28. Vissers ME, Cohen MX, Geurts HM. Brain connectivity and high functioning autism: a promising path of research that needs refined models, methodological convergence, and stronger behavioral links. Neurosci Biobehav Rev. 2012;36(1):604-625.

29. Gotts SJ, Simmons WK, Milbury LA, Wallace GL, Cox RW, Martin A. Fractionation of social brain circuits in autism spectrum disorders. Brain. 2012;135(Pt 9):2711-2725. 
30. Iacoboni M. Failure to deactivate in autism: the co-constitution of self and other. Trends Cogn Sci. 2006;10(10):431-433.

31. Buckner RL, Vincent JL. Unrest at rest: default activity and spontaneous network correlations. Neuroimage. 2007;37(4):1091-1096; discussion 1097-1099.

32. Monk CS, Peltier SJ, Wiggins JL, et al. Abnormalities of intrinsic functional connectivity in autism spectrum disorders. Neuroimage. 2009;47(2):764-772.

33. Dinstein I, Thomas C, Humphreys K, Minshew N, Behrmann M, Heeger DJ. Normal movement selectivity in autism. Neuron. 2010; 66(3):461-469.

34. Rasmussen P, Börjesson O, Wentz E, Gillberg C. Autistic disorders in Down syndrome: background factors and clinical correlates. Dev Med Child Neurol. 2001;43(11):750-754.

35. Lundström $S$, Chang Z, Råstam $M$, et al. Autism spectrum disorders and autistic like traits: similar etiology in the extreme end and the normal variation. Arch Gen Psychiatry. 2012;69(1):46-52.

36. Abrahams BS, Geschwind DH. Advances in autism genetics: on the threshold of a new neurobiology. Nat Rev Genet. 2008;9(5):341-355.

37. Engman ML, Lewensohn-Fuchs I, Mosskin M, Malm G. Congenital cytomegalovirus infection: the impact of cerebral cortical malformations. Acta Paediatr. 2010;99(9):1344-1349.

38. Dodds L, Fell DB, Shea S, Armson BA, Allen AC, Bryson S. The role of prenatal, obstetric and neonatal factors in the development of autism. J Autism Dev Disord. 2010;41(7):891-902.

39. Rasalam AD, Hailey H, Williams JH, et al. Characteristics of fetal anticonvulsant syndrome associated autistic disorder. Dev Med Child Neurol. 2005;47(8):551-555.

40. Sanders SJ, Ercan-Sencicek AG, Hus V, et al. Multiple recurrent de novo CNVs, including duplications of the 7q11.23 Williams syndrome region, are strongly associated with autism. Neuron. 2011;70(5): 863-885.

41. Levy D, Ronemus M, Yamrom B, et al. Rare de novo and transmitted copy-number variation in autistic spectrum disorders. Neuron. 2011;70(5):886-897.

42. Miller DT, Adam MP, Aradhya S, et al. Consensus statement: chromosomal microarray is a first-tier clinical diagnostic test for individuals with developmental disabilities or congenital anomalies. Am J Hum Genet. 2010;86(5):749-764.

43. Phelan K, McDermid HE. The 22q13.3 deletion syndrome (PhelanMcDermid syndrome). Mol Syndromol. 2012;2(3-5):186-201.

44. Wiśniowiecka-Kowalnik B, Nesteruk M, Peters SU, et al. Intragenic rearrangements in NRXN1 in three families with autism spectrum disorder, developmental delay, and speech delay. Am J Med Genet B Neuropsychiatr Genet. 2010;153B(5):983-993.

45. Peñagarikano $\mathrm{O}$, Geschwind $\mathrm{DH}$. What does CNTNAP2 reveal about autism spectrum disorder? Trends Mol Med. 2012;18(3):156-163.

46. Jamain S, Quach H, Betancur C, et al. Mutations of the X-linked genes encoding neuroligins NLGN3 and NLGN4 are associated with autism. Nat Genet. 2003;34(1):27-29.

47. Tuchman R, Cuccaro M. Epilepsy and autism: neurodevelopmental perspective. Curr Neurol Neurosci Rep. 2011;11(4):428-434.

48. Amiet C, Gourfinkel-An I, Bouzamondo A, et al. Epilepsy in autism is associated with intellectual disability and gender: evidence from a meta-analysis. Biol Psychiatry. 2008;64(7):577-582.

49. Saemundsen E, Ludvigsson P, Rafnsson V. Risk of autism spectrum disorders after infantile spasms: a population-based study nested in a cohort with seizures in the first year of life. Epilepsia. 2008;49(11): 1865-1870.

50. Steffenburg S, Steffenburg U, Gillberg C. Autism spectrum disorders in children with active epilepsy and learning disability: comorbidity, pre- and perinatal background, and seizure characteristics. Dev Med Child Neurol. 2003;45(11):724-730.

51. Parmeggiani A, Barcia G, Posar A, Raimondi E, Santucci M, Scaduto MC. Epilepsy and EEG paroxysmal abnormalities in autism spectrum disorders. Brain Dev. 2010;32(9):783-789.

52. Tuchman R, Cuccaro M, Alessandri M. Autism and epilepsy: historical perspective. Brain Dev. 2010;32(9):709-718.
53. Wu JY, Kuban KC, Allred E, Shapiro F, Darras BT. Association of Duchenne muscular dystrophy with autism spectrum disorder. $J$ Child Neurol. 2005;20(10):790-795.

54. Ekström AB, Hakenäs-Plate L, Samuelsson L, Tulinius M, Wentz E. Autism spectrum conditions in myotonic dystrophy type 1: a study on 57 individuals with congenital and childhood forms. Am J Med Genet B Neuropsychiatr Genet. 2008;147B(6):918-926.

55. Guevara-Campos J, González-Guevara L, Briones P, et al. Autism associated to a deficiency of complexes III and IV of the mitochondrial respiratory chain. Invest Clin. 2010;51(3):423-431.

56. Barbaro J, Dissanayake C. Autism spectrum disorders in infancy and toddlerhood: a review of the evidence on early signs, early identification tools, and early diagnosis. J Dev Behav Pediatr. 2009;30(5): $447-459$.

57. Baron-Cohen S, Allen J, Gillberg C. Can autism be detected at 18 months? The needle, the haystack, and the CHAT. Br J Psychiatry. 1992;161:839-843.

58. Robins DL, Fein D, Barton ML, Green JA. The Modified Checklist for Autism in Toddlers: an initial study investigating the early detection of autism and pervasive developmental disorders. J Autism Dev Disord. 2001;31(2):131-144.

59. Nygren G, Sandberg E, Gillstedt F, Ekeroth G, Arvidsson T, Gillberg C. A new screening programme for autism in a general population of Swedish toddlers. Res Dev Disabil. 2012;33(4):1200-1210.

60. Richdale AL, Schreck KA. Sleep problems in autism spectrum disorders: prevalence, nature, and possible biopsychosocial aetiologies. Sleep Med Rev. 2009;13(6):403-411.

61. Van Tongerloo MA, Bor HH, Lagro-Janssen AL. Detecting autism spectrum disorders in the general practitioner's practice. J Autism Dev Disord. 2012;42(8):1531-1538.

62. Keen DV. Childhood autism, feeding problems and failure to thrive in early infancy: seven case studies. Eur Child Adolesc Psychiatry. 2008; 17(4):209-216.

63. Nadel S, Poss JE. Early detection of autism spectrum disorders: screening between 12 and 24 months of age. J Am Acad Nurse Pract. 2007;19(8):408-417.

64. Peacock G, Lin SC. Enhancing early identification and coordination of intervention services for young children with autism spectrum disorders: report from the Act Early Regional Summit Project. Disabil Health J. 2012;5(1):55-59.

65. Eriksson MA, Westerlund J, Hedvall A, Amark P, Gillberg C, Fernell E. Medical conditions affect the outcome of early intervention in preschool children with autism spectrum disorders. Eur Child Adolesc Psychiatry. 2013;22(1):23-33.

66. Gillberg C, Ehlers S, Schaumann H, et al. Autism under age 3 years: a clinical study of 28 cases referred for autistic symptoms in infancy. J Child Psychol Psychiatry. 1990;31(6):921-934.

67. Lord C, Risi S, DiLavore PS, Shulman C, Thurm A, Pickles A. Autism from 2 to 9 years of age. Arch Gen Psychiatry. 2006;63(6):694-701.

68. Rondeau E, Klein LS, Masse A, Bodeau N, Cohen D, Guilé JM. Is pervasive developmental disorder not otherwise specified less stable than autistic disorder? A meta-analysis. J Autism Dev Disord. 2011;41(9):1267-1276.

69. Callahan K, Shukla-Mehta S, Magee S, Wie M. ABA versus TEACCH: the case for defining and validating comprehensive treatment models in autism. J Autism Dev Disord. 2010;40(1):74-88.

70. Smith T, Eikeseth SO. Ivar lovaas: pioneer of applied behavior analysis and intervention for children with autism. J Autism Dev Disord. 2011;41(3):375-378.

71. Mesibov GB, Shea V. The TEACCH program in the era of evidencebased practice. J Autism Dev Disord. 2010;40(5):570-579.

72. Parr J. Autism. Clin Evid (Online). 2010;2010:0322.

73. Fernell E, Hedvall A, Westerlund J, et al. Early intervention in 208 Swedish preschoolers with autism spectrum disorder: a prospective naturalistic study. Res Dev Disabil. 2011;32(6):2092-2101.

74. Reichow B, Barton EE, Boyd BA, Hume K. Early intensive behavioral intervention (EIBI) for young children with autism spectrum disorders (ASD). Cochrane Database Syst Rev. 2012;10:CD009260. 
75. Eldevik S, Hastings RP, Hughes JC, Jahr E, Eikeseth S, Cross S. Meta-analysis of early intensive behavioral intervention for children with autism. J Clin Child Adolesc Psychol. 2009;38(3):439-450.

76. Virués-Ortega J. Applied behavior analytic intervention for autism in early childhood: meta-analysis, meta-regression and dose-response meta-analysis of multiple outcomes. Clin Psychol Rev. 2010; 30(4):387-399.

77. Lovaas OI. Behavioral treatment and normal educational and intellectual functioning in young autistic children. J Consult Clin Psychol. 1987;55(1):3-9.

78. Schopler E, Short A, Mesibov G. Relation of behavioral treatment to "normal functioning": comment on Lovaas. J Consult Clin Psychol. 1989;57(1):162-164.

79. Eikeseth S, Smith T, Jahr E, Eldevik S. Intensive behavioral treatment at school for 4- to 7-year-old children with autism: a 1-year comparison controlled study. Behav Modif. 2002;26(1):49-68.

80. Sallows GO, Graupner TD. Intensive behavioral treatment for children with autism: four-year outcome and predictors. Am J Ment Retard. 2005;110(6):417-438.

81. Remington B, Hastings RP, Kovshoff H, et al. Early intensive behavioral intervention: outcomes for children with autism and their parents after two years. Am J Ment Retard. 2007;112(6):418-438.

82. Eikeseth S. Outcome of comprehensive psycho-educational interventions for young children with autism. Res Dev Disabil. 2009; 30(1):158-178.

83. Hayward D, Eikeseth S, Gale C, Morgan S. Assessing progress during treatment for young children with autism receiving intensive behavioural interventions. Autism. 2009;13(6):613-633.

84. Dawson G, Rogers S, Munson J, et al. Randomized, controlled trial of an intervention for toddlers with autism: the Early Start Denver Model. Pediatrics. 2010;125(1):e17-e23.

85. Freitag CM, Feineis-Matthews S, Valerian J, Teufel K, Wilker C. The Frankfurt early intervention program FFIP for preschool aged children with autism spectrum disorder: a pilot study. J Neural Transm. 2012; 119(9):1011-1021.

86. Rogers SJ, Estes A, Lord C, et al. Effects of a brief Early Start Denver model (ESDM)-based parent intervention on toddlers at risk for autism spectrum disorders: a randomized controlled trial. J Am Acad Child Adolesc Psychiatry. 2012;51(10):1052-1065.

87. Leichsenring F. Randomized controlled versus naturalistic studies: a new research agenda. Bull Menninger Clin. 2004;68(2):137-151.

88. Graham HK. The trials of trials. Dev Med Child Neurol. 2007; 49(3): 163 .

89. Rosenbaum P. The randomized controlled trial: an excellent design, but can it address the big questions in neurodisability? Dev Med Child Neurol. 2010;52(2):111.

90. Reed P, Osborne LA, Corness M. Brief report: relative effectiveness of different home-based behavioral approaches to early teaching intervention. J Autism Dev Disord. 2007;37(9):1815-1821.

91. Vismara LA, Rogers SJ. Behavioral treatments in autism spectrum disorder: what do we know? Annu Rev Clin Psychol. 2010;6:447-468.

92. Darrou C, Pry R, Pernon E, Michelon C, Aussilloux C, Baghdadli A. Outcome of young children with autism: does the amount of intervention influence developmental trajectories? Autism. 2010;14(6):663-677.

93. Coolican J, Smith IM, Bryson SE. Brief parent training in pivotal response treatment for preschoolers with autism. J Child Psychol Psychiatry. 2010;51(12):1321-1330.

94. Dawson G, Burner K. Behavioral interventions in children and adolescents with autism spectrum disorder: a review of recent findings. Curr Opin Pediatr. 2011;23(6):616-620.

95. Granpeesheh D, Tarbox J, Dixon DR, Carr E, Herbert M. Retrospective analysis of clinical records in 38 cases of recovery from autism. Ann Clin Psychiatry. 2009;21(4):195-204.

96. Billstedt E, Gillberg IC, Gillberg C. Autism after adolescence: population-based 13- to 22-year follow-up study of 120 individuals with autism diagnosed in childhood. JAutism Dev Disord. 2005;35(3): $351-360$.
97. Gillberg C, Steffenburg S. Outcome and prognostic factors in infantile autism and similar conditions: a population-based study of 46 cases followed through puberty. J Autism Dev Disord. 1987;17(2):273-287.

98. Cederlund M, Hagberg B, Billstedt E, Gillberg IC, Gillberg C. Asperger syndrome and autism: a comparative longitudinal follow-up study more than 5 years after original diagnosis. J Autism Dev Disord. 2008;38(1):72-85.

99. Howlin P, Magiati I, Charman T. Systematic review of early intensive behavioral interventions for children with autism. Am J Intellect Dev Disabil. 2009;114(1):23-41.

100. Reichow B. Overview of meta-analyses on early intensive behavioral intervention for young children with autism spectrum disorders. J Autism Dev Disord. 2012;42(4):512-520.

101. Ospina MB, Krebs Seida J, Clark B, et al. Behavioural and developmental interventions for autism spectrum disorder: a clinical systematic review. PloS One. 2008;3(11):e3755.

102. Warren Z, McPheeters ML, Sathe N, Foss-Feig JH, Glasser A, VeenstraVanderweele J. A systematic review of early intensive intervention for autism spectrum disorders. Pediatrics. 2011;127(5):e1303-e1311.

103. Spreckley M, Boyd R. Efficacy of applied behavioral intervention in preschool children with autism for improving cognitive, language, and adaptive behavior: a systematic review and meta-analysis. $J$ Pediatr. 2009;154(3):338-344.

104. Klintwall L, Gillberg C, Bölte S, Fernell E. The efficacy of intensive behavioral intervention for children with autism: a matter of allegiance? J Autism Dev Disord. 2012;42(1):139-140.

105. Chakrabarti S, Fombonne E. Pervasive developmental disorders in preschool children. JAMA. 2001;285(24):3093-3099.

106. Yeargin-Allsopp M, Rice C, Karapurkar T, Doernberg N, Boyle C, Murphy C. Prevalence of autism in a US metropolitan area. JAMA. 2003;289(1):49-55.

107. Baird G, Simonoff E, Pickles A, et al. Prevalence of disorders of the autism spectrum in a population cohort of children in South Thames: the Special Needs and Autism Project (SNAP). Lancet. 2006;368(9531):210-215.

108. O'Brien G, Pearson J. Autism and learning disability. Autism. 2004; $8(2): 125-140$.

109. Ehlers S, Gillberg C. The epidemiology of Asperger syndrome: a total population study. J Child Psychol Psychiatry. 1993;34(8): 1327-1350.

110. Gillberg C, Billstedt E. Autism and Asperger syndrome: coexistence with other clinical disorders. Acta Psychiatr Scand. 2000;102(5): 321-330.

111. Simonoff E, Pickles A, Charman T, Chandler S, Loucas T, Baird G. Psychiatric disorders in children with autism spectrum disorders: prevalence, comorbidity, and associated factors in a population-derived sample. J Am Acad Child Adolesc Psychiatry. 2008;47(8):921-929.

112. Gillberg C, Kadesjö B. Why bother about clumsiness? The implications of having developmental coordination disorder (DCD). Neural Plast. 2003;10(1-2):59-68.

113. Zappella M. Early-onset Tourette syndrome with reversible autistic behaviour: a dysmaturational disorder. Eur Child Adolesc Psychiatry. 2002;11(1):18-23.

114. DeLong GR, Dwyer JT. Correlation of family history with specific autistic subgroups: Asperger's syndrome and bipolar affective disease. J Autism Dev Disord. 1988;18(4):593-600.

115. Ghaziuddin M, Ghaziuddin N, Greden J. Depression in persons with autism: implications for research and clinical care. J Autism Dev Disord. 2002;32(4):299-306.

116. Unenge Hallerbäck M, Lugnegård T, Gillberg C. Is autism spectrum disorder common in schizophrenia? Psychiatry Res. 2012;198(1):12-17.

117. Lugnegård T, Hallerbäck MU, Gillberg C. Personality disorders and autism spectrum disorders: what are the connections? Compr Psychiatry. 2012;53(4):333-340.

118. Hattier MA, Matson JL, Belva BC, Horovitz M. The occurrence of challenging behaviours in children with autism spectrum disorders and atypical development. Dev Neurorehabil. 2011;14(4):221-229. 
119. Maskey M, Warnell F, Parr JR, Le Couteur A, McConachie H. Emotional and behavioural problems in children with autism spectrum disorder. J Autism Dev Disord. Epub August 16, 2012.

120. Brooks-Kayal A. Epilepsy and autism spectrum disorders: are there common developmental mechanisms? Brain Dev. 2010;32(9): 731-738.
121. Danielsson S, Gillberg IC, Billstedt E, Gillberg C, Olsson I. Epilepsy in young adults with autism: a prospective population-based follow-up study of 120 individuals diagnosed in childhood. Epilepsia. 2005;46(6):918-923.

\section{Publish your work in this journal}

Clinical Epidemiology is an international, peer-reviewed, open access journal focusing on disease and drug epidemiology, identification of risk factors and screening procedures to develop optimal preventative initiatives and programs. Specific topics include: diagnosis, prognosis, treatment, screening, prevention, risk factor modification, systematic

Submit your manuscript here: http://www.dovepress.com/clinical-epidemiology-journal

\section{Dovepress}

reviews, risk \& safety of medical interventions, epidemiology \& biostatical methods, evaluation of guidelines, translational medicine, health policies \& economic evaluations. The manuscript management system is completely online and includes a very quick and fair peer-review system, which is all easy to use. 